\title{
Currículo integrado e Educação politécnica: concepções e percepções no Ensino Médio Integrado
}

\author{
Integrated curriculum and politechnical Education: conceptions and \\ perceptions in Integrated High School
}

Recebido: 07/04/2020 | Revisado: 26/10/2020 | Aceito: 11/01/2021 | Publicado: $17 / 05 / 2021$

Claudia Maria Bezerra da Silva ORCID: https://orcid.org/0000-0003-19587772

Universidade Federal de Pernambuco E-mail: claudiambezerra@yahoo.com.br

Como citar:

SILVA, C. M. B.; Currículo integrado e Educação politécnica: concepções e percepções no Ensino Médio Integrado. Revista Brasileira da Educação

Profissional e Tecnológica, [S.I.], v. 1, n. 20, p. e10657, maio. 2021. ISSN 24471801.

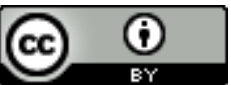

This work is licensed under a Creative Commons Attribution 4.0 Unported License.

\section{Resumo}

Este artigo apresenta uma pesquisa que tem como objetivo analisar as concepções e as percepções sobre o currículo integrado do ensino médio com a formação profissional, numa discussão na perspectiva da educação politécnica que concebe a formação humana plena. Foi realizada a revisão da literatura, análise documental e aplicação de questionários com professores e pedagogos. Os achados da pesquisa indicam que existem percepções que apontam para um currículo justaposto cuja proposta coaduna com uma dualidade entre formação geral e profissional, sem integração curricular. Conclui-se que cabe a necessidade de reflexão sobre os fundamentos do Ensino Médio Integrado para que o currículo e a prática docente estejam na direção da educação politécnica.

Palavras-chave: Currículo integrado. Educação politécnica. Ensino Médio Integrado.

\begin{abstract}
This article presents a research that aimed to analyze the conceptions and perceptions about the integrated curriculum of high school with professional education, in a discussion from the perspective of polytechnic education that sees full human formation. Literature review, document analysis and questionnaires with teachers and pedagogues were performed. The research findings indicate that there are perceptions that point to a juxtaposed curriculum whose proposal is consistent with a duality between general and technical training, without curricular integration. It is concluded that there is a need for reflection on the fundamentals of integrated high school so that the curriculum and teaching practice are in the direction of polytechnic education.
\end{abstract}

Keywords: Integrated curriculum. Polytechnic education. Integrated High School. 


\section{INTRODUÇÃO}

A integração do ensino médio com a formação profissional assegurada pelo Decreto $\mathrm{n}^{0}$ 5.154/2004 trouxe a possibilidade de superação do histórico educacional brasileiro caracterizado pela distinção entre os que pensavam daqueles que apenas executavam uma função. Eram ofertas pautadas no dualismo da formação propedêutica para a elite e, para os menos favorecidos socioeconomicamente, uma formação voltada para mão de obra em atendimento às necessidades do mercado de trabalho.

De encontro a esse histórico, o Ensino Médio Integrado (EMI) está fundamentado na concepção de que teoria e prática caminhem juntas na mesma formação. Assim, não se trata de juntar disciplinas e/ou cargas horárias, mas organizar o currículo de modo a relacionar os conhecimentos gerais e profissionais, a cultura e o trabalho, o humanismo e a tecnologia, resgatando o princípio da formação humana integral (RAMOS, 2010).

A formação humana integral no EMI pode ser construída tendo como perspectiva a educação politécnica. É um ideário que, de acordo com Marx e Engels (2011), concebe a preparação plena do homem, de modo a propiciar uma intervenção consciente na realidade e a sua emancipação. Nesse movimento, os alunos tem acesso a disciplinas equivalentes à base nacional comum referente ao ensino médio e à formação profissional escolhida, preparando tanto para prosseguir nos estudos quanto para ingressar no mundo do trabalho.

Diante do exposto, tomamos como objetivo geral desta pesquisa: analisar as concepções e percepções sobre o currículo integrado do ensino médio com a formação profissional, numa discussão na perspectiva da educação politécnica que concebe a formação humana plena. Para tanto, a construção teórica foi realizada por meio da revisão da literatura e análise de documentos e, como instrumento de pesquisa, a aplicação de questionários.

O referencial para fundamentar as discussões está pautado em autores que se dedicam à investigação sobre a educação politécnica, EMI e currículo, tais como: Sacristán (2010), Santomé (1998), Ramos (2010), Marx e Engels (2011), entre outros. Em relação à análise de documentos, o levantamento do material ocorreu tendo como fontes os oficiais do Ministério da Educação como a Lei de Diretrizes e Bases da Educação Nacional (LDB) № 9.394/1996 e o Decreto oㅜ 5.154/2004. A pesquisa foi desenvolvida no Instituto Federal de Educação, Ciência e Tecnologia de Pernambuco (IFPE)/Campus Recife, onde foram consultados os Planos Pedagógicos de Curso (PPC's) e aplicados questionários com professores e pedagogos.

Para melhor localizar o leitor, o artigo está estruturado de modo a refletir sobre as compreensões teóricas de currículo, a integração curricular no EMI e a perspectiva da formação politécnica. Em seguida, é apresentada a metodologia da pesquisa e as análises dos PPC's e das percepções sobre o currículo integrado no âmbito do IFPE/Campus Recife. 


\section{REFLEXÕES SOBRE CURRÍCULO}

O currículo é compreendido como a organização de uma trajetória em graus de complexidade que permite a transição escolar do aluno em busca do pleno desenvolvimento (SACRISTÁN, 2010; YOUNG, 2007). Esse percurso envolve conteúdos, competências e metodologias, adquirindo forma e significado à medida que sofre transformações dentro das atividades pedagógicas. Assim, mesmo que existam referências, é possível considerar a cultura e o estudo de problemas da localidade numa tentativa de ressignificar os conceitos.

O currículo, então, norteia e organiza o trabalho, mas não deve ser visto como algo prescrito e rígido a ser seguido por todos. Conforme Young (2007) é importante considerar o conhecimento local e cotidiano que os alunos levam para a escola, encontrando nesse contexto a possibilidade de os conteúdos fazerem sentido. Tornase uma oportunidade para transmitir as opiniões, as crenças e a cultura modeladas pelos sujeitos, retirando a neutralidade.

Além de fazer com que o currículo tenha sentido no contexto em que é trabalhado, outro movimento necessário é a integração curricular. Essa questão traz a compreensão do conhecimento como algo que se renova a partir do diálogo entre as diversas áreas do saber e cultiva a postura crítica, criativa e investigativa. É uma alternativa que busca contemplar a compreensão global do conhecimento e promover maiores parcelas de interdisciplinaridade e contextualização, contribuindo para superar a fragmentação do ensino.

\subsection{A INTEGRAÇÃO CURRICULAR NO EMI}

Aproximar educação e trabalho é previsto na LDB no 9.394/1996 que indica que "a educação escolar deverá vincular-se ao mundo do trabalho e à prática social", com a finalidade de obter "[...] o pleno desenvolvimento da pessoa, seu preparo para o exercício da cidadania e sua qualificação para o trabalho". Além disso, aponta para o ensino médio como etapa final da educação básica que proporcione "a compreensão dos fundamentos científico-tecnológicos dos processos produtivos, relacionando a teoria com a prática" (BRASIL, 1996).

Esses fragmentos permitem a reflexão sobre a educação como espaço de formação para o trabalho e construção da emancipação humana. É uma concepção assegurada no Decreto no 5.154/2004 que traz a possibilidade do ensino médio integrado ao profissional, de modo a consolidar a formação centrada no trabalho, na ciência, na tecnologia e na cultura. Reflete, assim, um ganho que consiste em integrar os conhecimentos tendo como elemento fundamental a superação da dualidade entre formação profissional e acadêmica.

A organização do currículo no EMI é norteada pela Resolução no 06/2012 que define como diretrizes: 
II - o núcleo politécnico comum correspondente a cada eixo tecnológico em que se situa o curso, que compreende os fundamentos científicos, sociais, organizacionais, econômicos, políticos, culturais, ambientais, estéticos e éticos que alicerçam as tecnologias e a contextualização do mesmo no sistema de produção social;

III - os conhecimentos e as habilidades nas áreas de linguagens e códigos, ciências humanas, matemática e ciências da natureza, vinculados à Educação Básica deverão permear o currículo dos cursos técnicos de nível médio, de acordo com as especificidades dos mesmos, como elementos essenciais para a formação e o desenvolvimento profissional do cidadão; IV - a pertinência, a coerência, a coesão e a consistência de conteúdos, articulados do ponto de vista do trabalho assumido como princípio educativo, contemplando as necessárias bases conceituais e metodológicas;

V - a atualização permanente dos cursos e currículos, estruturados em ampla base de dados, pesquisas e outras fontes de informação pertinentes. (BRASIL, 2012).

Desse modo, o currículo busca habilitar o aluno para o exercício autônomo e crítico da profissão, se tratando, portanto de superar:

[...] a redução da preparação para o trabalho ao seu aspecto operacional, simplificado, escoimado dos conhecimentos que estão na sua gênese científico-tecnológica e na sua apropriação histórico-social. Como formação humana, o que se busca é garantir ao adolescente, ao jovem e ao adulto trabalhador o direito a uma formação completa para a leitura do mundo e para a atuação como cidadão pertencente a um país, integrado dignamente à sua sociedade política. (CIAVATTA, 2005, p. 85).

A formação integrada remete ao sentido de completude e compreensão das partes no seu todo, o que implica tratar a educação como uma totalidade social com múltiplas mediações históricas que se concretizam nos processos (CIAVATTA, 2005). Nessa perspectiva, nenhum conhecimento é apenas relacionado à formação geral, já que estrutura objetivos no campo do trabalho; bem como não é somente específico, pois os conceitos relacionados à produção são formulados articuladamente à ciência básica.

A importância dessa organização curricular está apoiada no acesso ao conhecimento científico e cultural ao mesmo tempo em que desenvolve a formação profissional. O diálogo entre diferentes conhecimentos e práticas educativas acaba sendo facilitado, ultrapassando a abordagem que prioriza disciplinas isoladas e fechadas em sua área. É um ideário que pode proporcionar a ampliação do campo de conhecimento do aluno, construindo melhores condições para a vida social e para o mundo do trabalho.

O currículo do EMI, conforme Ramos (2010), deve ter como pressupostos:

a) O sujeito é concebido como ser histórico-social concreto, capaz de transformar a realidade em que vive; b) a finalidade do processo educativo visa à formação humana como síntese de formação básica e formação para o trabalho; c) o trabalho é princípio educativo no sentido de permitir, concretamente, a compreensão do significado econômico, social, histórico, político e cultural das ciências e das artes; d) a seleção de conteúdos é baseada numa epistemologia que considere a unidade de conhecimentos 
gerais e conhecimentos específicos e o processo de ensino-aprendizagem se apoia numa metodologia que permita a identificação das especificidades desses conhecimentos quanto à sua historicidade, finalidades e potencialidades; e) o processo de ensino visa à construção conjunta de conhecimentos gerais e específicos, no sentido de que os primeiros fundamentam os segundos e esses evidenciam o caráter produtivo concreto dos primeiros; f) a profissionalização não se limita à dimensão técnicooperacional dos processos de trabalho, mas se centra nos fundamentos científico-tecnológicos, sócio-históricos e culturais da produção moderna em geral e da área profissional em particular; g) a compreensão histórica do processo de produção da área profissional e de suas contradições, como parte de uma totalidade constituída pela produção material e pelas relações sociais modernas, possibilita uma formação politécnica e omnilateral dos sujeitos. (RAMOS, 2010, p. 52-53).

Sob essas premissas, a formação profissional adquire um significado do trabalho como necessário para a constituição do homem como ser histórico-social que cria e modifica a própria existência, produzindo saberes e agindo social e politicamente. $O$ trabalho é compreendido, então, como princípio educativo propondo mais do que técnicas metodológicas ou didáticas para o ensino e a aprendizagem. É um processo em que o trabalho orienta a educação a desenvolver o aluno de maneira produtiva, científica e cultural (RAMOS, 2017), cabendo a intencionalidade de que "[...] através da ação educativa os indivíduos/coletivos compreendam enquanto vivenciam e constroem a própria formação" (MOURA, 2007, p. 22).

O currículo construído a partir de elementos da cultura, do trabalho, da experiência humana e do conhecimento historicamente produzido pela sociedade acaba por socializar e formar os sujeitos "[...] para serem cidadãos e cidadãs solidários, responsáveis e democráticos" (SANTOMÉ, 1998, p. 95). É uma tentativa de anular o modelo estanque de estruturação curricular em que as disciplinas e os conteúdos são trabalhados de forma fragmentada, para promover uma visão do todo que atenda ao:

[...] interesse em obter uma integração de campos de conhecimento e experiência que facilitem uma compreensão mais reflexiva e crítica da realidade, ressaltando não só dimensões centradas em conteúdos culturais, mas também o domínio dos processos necessários para conseguir alcançar conhecimentos concretos e, ao mesmo tempo, a compreensão de como se elabora, produz e transforma o conhecimento, bem como as dimensões éticas inerentes a essa tarefa. (SANTOMÉ, 1998, p. 27).

Superar a fragmentação permite que os conteúdos sejam organizados e desenvolvidos em sua totalidade concreta, contribuindo para a construção do conhecimento de forma global. Isso exige conhecer as relações existentes entre as disciplinas, colocando-as numa perspectiva relacional em que as fronteiras tornam-se pouco nítidas "[...] no seu campo científico de origem (disciplinaridade) e em relação a outros de campos distintos (interdisciplinaridade)" (RAMOS, 2017, p. 34).

A exploração das potencialidades de cada disciplina e a constante articulação entre a formação geral e profissional pode permitir a apropriação significativa capaz de contextualizar o conhecimento disponibilizado para as situações do dia a dia. A integração curricular, portanto, não se caracteriza como mera oferta de disciplinas, 
mas na constante relação entre elas. Quanto à prática educativa, demanda planejamento e flexibilidade, além da reflexão de que o domínio enciclopédico de conhecimentos desarticulados deve estar ultrapassado.

\section{A PERSPECTIVA DA EDUCAÇÃO POLITÉCNICA}

A educação politécnica é compreendida como a preparação multilateral do homem, em suas capacidades físicas e mentais, na tentativa de superar a divisão entre os que planejam e os que executam em direção à emancipação social (MARX; ENGELS, 2011). Desse modo, para que seja realizada, são combinados trabalho e educação, vinculando a formação pelo e para o trabalho manual e o intelectual.

O processo formativo ocorre, então, diretamente nas situações reais do contexto produtivo, tomando o trabalho como constituinte do ser social (MARX, 1996) e contemplando:

1) Educação intelectual.

2) Educação corporal, tal como a que se consegue com os exercícios de ginástica e militares.

3) Educação tecnológica, que recolhe os princípios gerais e de caráter científico de todo o processo de produção e, ao mesmo tempo, inicia as crianças e os adolescentes no manejo de ferramentas elementares dos diversos ramos industriais. (MARX; ENGELS, 2011, p. 85).

Assim estruturada, a formação acontece de maneira articulada, se sustentando sobre três bases educacionais: a intelectual contempla a aquisição do conhecimento científico e cultural que permitiria melhor compreender o processo produtivo e fortalecer o homem nas disputas políticas; a corporal contribuiria na recuperação física pelo trabalho na fábrica; e a tecnológica, para domínio dos fundamentos científicos e manejo dos processos de produção.

O desenvolvimento desses três aspectos significava a possibilidade da classe trabalhadora ampliar o seu escopo de trabalho, não se limitando ao mero manejo de máquinas. É uma busca pela substituição do "[...] indivíduo-fragmento, o mero portador de uma função social de detalhe, pelo indivíduo totalmente desenvolvido, para o qual diferentes funções sociais são modos de atividade que se alternam" (MARX; ENGELS, 2011, p. 97).

A educação politécnica favorece, então, a compreensão de todo o processo produtivo, superando a dicotomia entre teoria e prática. Afinal, uma prática esvaziada de teoria e uma teoria desprovida de prática discordam do entendimento de trabalho como processo integral que envolve todas as capacidades humanas em torno da realidade concreta (MARX, 1996).

Em conformidade com essa concepção, Saviani (2007) classifica a politecnia como o domínio dos fundamentos científicos das diferentes técnicas, concentrandose nas modalidades que dão base à multiplicidade dos processos de produção moderna existentes. É um pensamento que aponta para o desenvolvimento de todas 
as potencialidades do aluno, dando respaldo a uma perspectiva de superação da dicotomia entre trabalho manual e intelectual.

A partir da educação politécnica, é possível perceber que somente uma educação que valorize a formação nas suas dimensões técnica e científica pode estar comprometida em combater a concepção do homem como força produtiva fundado na divisão das classes sociais. Neste trabalho, assumimos a concepção de EMI como caminho possível para a educação politécnica, de modo a proporcionar as bases necessárias para a construção de uma sociedade mais justa e emancipatória.

\section{METODOLOGIA}

A construção teórica desta pesquisa foi realizada por meio de revisão da literatura e análise de documentos, o que permitiu o conhecimento a partir de enfoques e abordagens distintos, além de construir uma base que fundamentou os dados coletados nos questionários.

Para analisar as concepções sobre o currículo integrado do ensino médio com a formação profissional, a pesquisa teve como campo de estudo o IFPE/Campus Recife. O critério de escolha do local foi de uma instituição de Educação Profissional que ofertasse o EMI, requisito atendido pelo Campus. Na Instituição, percorremos dois caminhos: a análise dos PPC's e a aplicação de questionários com professores e pedagogos.

Os PPC's em questão foram dos cursos do EMI em: Edificações (IFPE, 2013a), Eletrônica (IFPE, 2014a), Eletrotécnica (IFPE, 2014b), Mecânica (IFPE, 2014c), Química (IFPE, 2014d), Saneamento (IFPE, 2013b) e Segurança do Trabalho (IFPE, 2014e). Essa análise se justifica pelo fato de os PPC's serem instrumentos teórico-metodológicos que definem as disciplinas, a metodologia, os saberes e os princípios norteadores dos cursos, indicando como acontece a integração curricular.

A coleta de dados ocorreu por meio de questionário com a participação de 56 professores e 5 pedagogos. A aplicação com os professores foi feita por meio do Google Forms, com link enviado por e-mail, e com os pedagogos foi entregue impresso e pessoalmente. Para escolha dos sujeitos, o critério estabelecido com relação aos professores foi o de lecionar nos cursos do EMI, reunindo professores das disciplinas de formação geral e profissional. Já com os pedagogos, era necessário atuar acompanhando o processo de ensino e de aprendizagem nos cursos do EMI.

Com os dados coletados, a análise e interpretação procurou dar significado às respostas a partir da categorização e análise de conteúdo na perspectiva de Bardin (2016). Assim, os dados foram agrupados através da utilização de uma frase, em que foi possível fazer emergir do texto uma unidade temática com base na referência da pesquisa.

Sobre o princípio ético, a pesquisa foi encaminhada à Plataforma Brasil, tendo sido aprovada por Comitê de Ética e Pesquisa com parecer consubstanciado de no 2.982.805. Além disso, teve anuência da direção geral do IFPE/Campus Recife para que a coleta de dados fosse realizada na Instituição. A todos os participantes foi apresentado o Termo de Consentimento Livre e Esclarecido com informações sobre a pesquisa e compromisso em zelar pela privacidade e sigilo dos dados. 
Posto isso, todos os dados foram tratados de forma a garantir o anonimato dos sujeitos, sendo identificados da seguinte forma: os professores como P1, P2,... P56; e os pedagogos como C1, C2,... C5.

Neste artigo, são citados os fragmentos dos depoimentos de 5 professores (P3; P11; P15; P44 ;P53) e de 1 pedagogo (C3).

\section{INTEGRACCÃO CURRICULAR NO EMI: O QUE DIZEM OS PLANOS PEDAGÓGICOS DOS CURSOS}

A reflexão caminha com o objetivo de analisar nos PPC's como estão colocados os aspectos pertinentes à integração curricular no EMI, tendo como pressuposto o ideário da formação politécnica.

Nesse diálogo, um ponto preocupante nos PPC's dos cursos de Eletrotécnica (IFPE, 2014b), Mecânica (IFPE, 2014c), Química (IFPE, 2014d) e Segurança do Trabalho (IFPE, 2014e) foi a ausência da fundamentação sobre os princípios históricos, filosóficos, pedagógicos e políticos do EMI. Apesar de remeter a uma formação com organicidade entre teoria e prática, nos documentos não há referência às discussões sobre a educação politécnica e a perspectiva de emancipação humana inerentes ao EMI. Os PPC's chegam, inclusive, a apresentar o curso como "profissionalizante" de nível médio ofertado na forma integrada (IFPE, 2014b; 2014c; 2014d; 2014e), o que remeteria ao risco de ser compreendido como mera formação para atender às demandas do mercado ou, ainda, de um curso de ensino médio justaposto ao profissional.

Tendo em vista que o pressuposto da educação politécnica que norteia o EMI vai além da inovação pedagógica ou curricular, cabe a necessidade de que os fundamentos do curso estejam claramente alinhados ao que é apregoado pela modalidade. É importante, portanto, que essa discussão esteja colocada nos PPC's para que exista a compreensão sobre os princípios do EMI, além de pertencimento dos docentes a uma modalidade que tem a educação como espaço de formação para o trabalho e construção da emancipação humana.

Por outro lado, os PPC's dos cursos de Edificações (IFPE, 2013a), Eletrônica (2014a) e Saneamento (2013b) trazem uma discussão fundamentada sobre a superação do dualismo entre o ensino propedêutico e profissional. Apresentam, assim, a politecnia como base para formar trabalhadores capazes de atuar como cidadãos integralmente desenvolvidos em todas as suas potencialidades, além de abordar: os princípios, o histórico e a concepção do EMI; a integração epistemológica de conteúdos; o trabalho, a ciência, a tecnologia e a cultura como dimensões indissociáveis da formação humana; o trabalho como princípio educativo; e a contextualização e interdisciplinaridade como princípios pedagógicos (IFPE, 2013a; 2013b; 2014a).

Para tanto, esses PPC's (IFPE, 2013a; 2013b; 2014a) apontam a importância de considerar o planejamento integrado das atividades de ensino, de modo que o aluno se aproprie do conhecimento para o trabalho e para a vida. Seria, então, uma formação pautada "[...] na perspectiva do estudante como sujeito social, que busca compreender criticamente o mundo e o lugar onde vive como realidades inseparáveis" (IFPE, 2013a, p. 49). 
Sobre a organização do percurso formativo, todos os PPC's trazem a duração do curso com total de oito períodos semestrais, com as matrizes curriculares elencando disciplinas agrupadas em três partes: a "Base Comum" abrange as áreas de linguagens, ciências humanas, matemática e ciências da natureza; a "Parte Diversificada" se relaciona à língua estrangeira, informática e relações humanas e no trabalho; e os "Conhecimentos Tecnológicos" com as áreas específicas da formação profissional (IFPE, 2013a; 2013b; 2014a; 2014b; 2014c; 2014d; 2014e).

$\mathrm{Na}$ perspectiva de um currículo integrado como pressuposto fundante dos cursos, o ponto comum nos documentos é a indicação de um trabalho pedagógico que possibilite apreender não apenas a teoria, mas também a prática dos princípios científicos e tecnológicos (IFPE, 2013a; 2013b; 2014a; 2014b; 2014c; 2014d; 2014e). É uma concepção que remete à proposta de educação politécnica, com a perspectiva de formar o aluno para a emancipação, e não unicamente como uma ponte para a entrada no mercado de trabalho.

O EMI norteado pela politecnia contempla o domínio dos princípios e da prática, mediante a incorporação da dimensão intelectual ao trabalho. Nessa direção, os PPC's dos cursos de Edificações (IFPE, 2013a), Eletrônica (IFPE, 2014a) e Saneamento (IFPE, 2013b) apresentam a proposta de considerar o trabalho como princípio educativo para a apropriação e a compreensão dos conhecimentos.

Uma proposta de formação que toma o trabalho como princípio educativo elabora a construção do conhecimento de modo a ampliar as capacidades, as potencialidades e os sentidos humanos (RAMOS, 2010). Assim, é importante que os conteúdos da parte profissional sejam investigados em suas múltiplas dimensões, apreendendo os conceitos como uma totalidade histórica e dialética.

É um movimento em que a integração dos conhecimentos gerais e profissionais se torna importante, sendo construída de modo a romper com as fragmentações que dificultam o desvelamento das contradições presentes na sociedade. Assim, a técnica do trabalho e a sua base científica são articuladas, ficando estreitamente ligados, conforme o apontado no PPC do curso de Eletrônica:

Os componentes curriculares do Ensino Médio devem ser articulados de uma forma harmoniosa e interdisciplinar de modo a desenvolver, nos estudantes, a visão necessária do universo dos conhecimentos científicos e da sua relação com a compreensão e atuação no mundo contemporâneo e no mundo do trabalho, em sua ação cotidiana, enquanto cidadão, bem como na sua futura atividade profissional, contribuindo na apreensão e utilização das tecnologias modernas. (IFPE, 2014a, p. 47).

Com uma organização curricular que integra componentes de formação geral e profissional para apreensão da teoria e da prática, foi possível constatar a busca por superar a fragmentação do saber nos PPC's analisados (IFPE, 2013a; 2013b; 2014a; 2014b; 2014c; 2014d; 2014e).

Por outro lado, algo que precisa ser pontuado sobre a estrutura dos documentos é que coexistem formatos que fundamentam uma formação emancipatória (IFPE, 2013a; 2013b; 2014a), mas também, outros que carecem de uma discussão maior sobre os princípios do EMI (IFPE, 2014b; 2014c; 2014d; 2014e). Como os PPC's fundamentam o planejamento e a prática docente, deixar claro os 
princípios do EMI se faz necessário para superar a possibilidade de um currículo fragmentado que apenas junta disciplinas do ensino médio e da formação profissional. É a importância de que o posto no documento e o praticado em sala de aula propiciem efetivamente uma educação para o mundo do trabalho e para a prática social.

\section{PERCEPÇÕES SOBRE A INTEGRAÇÃO DO CURRÍCULO NO EMI}

O texto caminha no sentido de refletir sobre as percepções dos professores e pedagogos do IFPE/Campus Recife a partir do questionamento sobre como ocorre a integração curricular no EMI. Após a análise, os dados remetem a: currículo justaposto e currículo integrado.

A percepção de um currículo justaposto situa a integração curricular no senso comum da formação básica agrupada à profissional. Seria o equivalente a duas formações que caminham lado a lado, mas sem integração, como percebemos nos fragmentos: "Percebo que não existe diálogo entre as disciplinas do ensino médio e da formação profissional, com trabalhos individuais em seus campos de conhecimentos." (P11); "Vejo dois currículos unidos em um curso, cada um com seus objetivos de formação, sem interdisciplinaridade entre as disciplinas e, menos ainda, entre as áreas." (P3). E ainda:

Observo que é preciso aprofundar a compreensão do que seja integrado. Parece que se faz um ajuntamento mecânico, ao estilo frankensteiniano, de corpos estranhos e não uma articulação mais refinada/articulada que justifique o termo. (P44).

A partir desses dados, notamos uma formação que ora caminha para um ensino propedêutico, que prepara os alunos para aprovação na universidade; ora para um ensino profissional, que pretende apenas formar para o mercado de trabalho. Desconsidera, assim, a concepção do currículo integrado que, conforme Ramos (2010), proporciona uma unidade em seus princípios e objetivos, desenvolvendo possibilidades formativas que contemplam as múltiplas necessidades socioculturais e econômicas dos sujeitos que o constituem.

Os limites no diálogo entre as áreas de formação geral e formação profissional indica que prevalece a lógica estruturante do currículo limitado pela linearidade dos saberes, engessando as possibilidades de uma ação integradora. Com práticas isoladas, meramente funcionais e mecânicas, o EMl é reduzido a um simples:

[...] adestramento em uma determinada habilidade sem o conhecimento dos fundamentos dessa habilidade e, menos ainda, da articulação dessa habilidade com o conjunto do processo produtivo (SAVIANI, 2007, p. 161).

O ideário da integração curricular estabelece uma relação entre os conhecimentos, contribuindo para que o aluno se aproprie não só da técnica necessária para sua atividade profissional, mas também dos fundamentos e princípios que a norteiam. Como afirma Santomé (1998), o currículo integrado tem sido utilizado 
como tentativa de contemplar uma compreensão global do conhecimento e de promover maiores parcelas de interdisciplinaridade na sua construção. $O$ que se pretende é uma formação que consiga romper com a ideia da mera transmissão de técnicas, estabelecendo relações dinâmicas e dialéticas na integração dos conhecimentos.

Em uma visão contrária ao currículo justaposto, os dados apontaram para o currículo integrado, aproximando à concepção do EMI. Conforme P15: "O currículo é composto por dois campos de formações que se integram para uma formação completa do aluno". E ainda: "Disciplinas que seriam de formações distintas (ensino médio e trabalho) integradas para desenvolver competências e habilidades para a vida em sociedade e no trabalho" (P53); ou "O currículo é integrado formando o aluno na educação básica e profissional, na perspectiva da união de conhecimentos" (C3).

Esses fragmentos caminham para uma perspectiva de integração curricular que busca romper com as dicotomias existentes entre geral e profissional, heranças de uma concepção fragmentária de formação humana.

O desafio de construir um currículo integrado parte da compreensão do processo de produção da área profissional como uma realidade concreta que precisa ser investigada e conhecida em suas múltiplas dimensões (RAMOS, 2010). Desse modo, a organização curricular possibilitará aos alunos a formação profissional sem, contudo, se restringir a uma educação que forme exclusivamente para o trabalho, equilibrando a capacidade manual e intelectual.

A integração em si não se dá apenas na forma de organização do currículo, mas da prática docente que acontece a partir dele. Isso implica a necessidade de um currículo bem estruturado e em metodologias alinhadas à concepção do EMI. Tendo em vista que, nesta pesquisa, os dados apontaram a existência de percepções de um currículo justaposto, cabe à Instituição uma reflexão com questionamentos como: Qual a concepção de EMI que estamos desenvolvendo? Qual o perfil do aluno que pretendemos formar? O que é integração curricular e como efetivá-la?

O debate, feito com a participação de todos os envolvidos no processo de ensino, deve trazer à tona as construções históricas, políticas, filosóficas e pedagógicas em relação ao EMI para que, na teoria e na prática, o currículo seja integrado.

\section{CONSIDERAÇÕES FINAIS}

Investigar o currículo integrado no âmbito do IFPE/Campus Recife constituiu um momento de confrontar as contribuições teóricas com a materialidade nos PPC's e a percepção dos sujeitos ligados ao processo de ensino da Instituição. Como resultado, nos PPC's analisados foi possível visualizar a indicação do currículo integrado e da educação politécnica, mas também que alguns documentos carecem de maior fundamentação sobre o EMI. Em relação às percepções dos professores e pedagogos, os dados apontaram que existem entendimentos de um currículo justaposto que vai de encontro à proposta da modalidade.

A integração curricular entre o ensino médio e a formação profissional coaduna com a perspectiva de uma educação politécnica que amplia as oportunidades educativas para o exercício da cidadania. Para que seja efetivada, 
demanda formação docente continuada, trabalho colaborativo e comprometimento com a formação integrada. Assim, finalizamos este artigo nos remetendo a Marx e Engels (2011), que afirmam tratar-se de uma opção política comprometida com o social, que resgata a unicidade entre o trabalho manual e intelectual, rompendo a fragmentação do conhecimento.

\section{REFERÊNCIAS}

BARDIN, L. Análise de conteúdo. São Paulo: Edições 70, 2016.

BRASIL. Ministério da Educação. Resolução no 6, de 20 de setembro de 2012. Defini as diretrizes curriculares nacionais para a educação profissional técnica de nível médio. Brasília, 2012. Disponível em:

http://portal. mec.gov.br/index .php?option=com docman\&view=download\&alias $=116$ 63-rceb006-12-pdf\&category slug=setembro-2012-pdf\&ltemid=30192. Acesso em: 15 abr. 2020.

BRASIL. Presidência da República. Decreto no 5.154, de 23 de julho de 2004. Regulamenta o $\S 2^{\circ}$ do art. 36 e os arts. 39 a 41 da Lei no 9.394, de 20 de dezembro de 1996, que estabelece as diretrizes e bases da educação nacional, e dá outras providências. Brasília, 2004. Disponível em:

http://www.planalto.gov.br/ccivil 03/ ato2004-2006/2004/decreto/d5154.htm. Acesso em: 31 jan. 2020.

BRASIL. Presidência da República. Lei no 9.394, de 20 de dezembro de 1996. Lei de Diretrizes e Bases da Educação Nacional. Brasília, 1996. Disponível em: www.planalto.gov.br/ccivil 03/leis/L9394.htm. Acesso em: 31 jan. 2020.

CIAVATTA, M. A formação integrada: a escola e o trabalho como lugares de memória e identidade. Trabalho Necessário, Niterói, v. 3, n. 3, p. 01-20, 2005. Disponível em: http://periodicos.uff.br/trabalhonecessario/issue/view/266. Acesso em: 21 dez. 2019.

INSTITUTO FEDERAL DE EDUCAÇÃO, CIÊNCIA E TECNOLOGIA DE PERNAMBUCO. Campus Recife. Plano Pedagógico de Curso Técnico Integrado ao Médio em Edificações. Recife, 2013a. Disponível em:

https://portal.ifpe.edu.br/campus/recife/cursos/tecnicos/integrados/edificacoes/projeto -pedagogico/ppc-edificacoes-integrado.pdf. Acesso em: 15 mar. 2020.

INSTITUTO FEDERAL DE EDUCAÇÃO, CIÊNCIA E TECNOLOGIA DE PERNAMBUCO. Campus Recife. Plano Pedagógico de Curso Técnico Integrado ao Médio em Eletrônica. Recife, 2014a. Disponível em:

https://portal.ifpe.edu.br/campus/recife/cursos/tecnicos/integrados/eletronica/projetopedagogico/ppc eletronica integrado.pdf. Acesso em: 15 mar. 2020.

INSTITUTO FEDERAL DE EDUCAÇÃO, CIÊNCIA E TECNOLOGIA DE PERNAMBUCO. Campus Recife. Plano Pedagógico de Curso Técnico Integrado ao Médio em Eletrotécnica. Recife, 2014b. Disponível em: https://portal.ifpe.edu.br/campus/recife/cursos/tecnicos/integrados/eletrotecnica/proje to-pedagogico/ppc-eletrotecnica-integrado-2014-versao-final.pdf. Acesso em: 15 mar. 2020. 
INSTITUTO FEDERAL DE EDUCAÇÃO, CIÊNCIA E TECNOLOGIA DE PERNAMBUCO. Campus Recife. Plano Pedagógico de Curso Técnico Integrado ao Médio em Mecânica. Recife, 2014c. Disponível em:

https://portal.ifpe.edu.br/campus/recife/cursos/tecnicos/integrados/mecanica/projetopedagogico/mecanica-curso-tecnico-integrado-plano-de-curso.pdf. Acesso em: 15 mar. 2020.

INSTITUTO FEDERAL DE EDUCAÇÃO, CIÊNCIA E TECNOLOGIA DE PERNAMBUCO. Campus Recife. Plano Pedagógico de Curso Técnico Integrado ao Médio em Química. Recife, 2014d. Disponível em:

https://portal.ifpe.edu.br/campus/recife/cursos/tecnicos/integrados/quimica/projetopedagogico/ppc-quimica-integrado 2014-recife.pdf. Acesso em: 15 mar. 2020.

INSTITUTO FEDERAL DE EDUCAÇÃO, CIÊNCIA E TECNOLOGIA DE PERNAMBUCO. Campus Recife. Plano Pedagógico de Curso Técnico Integrado ao Médio em Saneamento. Recife, 2013b. Disponível em: https://portal.ifpe.edu.br/campus/recife/cursos/tecnicos/integrados/saneamento/projet o-pedagogico/ppc saneamento integrado.pdf. Acesso em: 15 mar. 2020.

INSTITUTO FEDERAL DE EDUCAÇÃO, CIÊNCIA E TECNOLOGIA DE PERNAMBUCO. Campus Recife. Plano Pedagógico de Curso Técnico Integrado ao Médio em Segurança do Trabalho. Recife, 2014e. Disponível em: https://portal.ifpe.edu.br/campus/recife/cursos/tecnicos/integrados/seguranca-dotrabalho/projeto-pedagogico/projeto pedagogico seguranca integrado 2014-1.pdf. Acesso em: 15 mar. 2020.

MARX, K. O Capital: crítica da economia política. Livro 1, v. 1. São Paulo: Nova Cultural Ltda, 1996.

MARX, K.; ENGELS, F. Textos sobre educação e ensino. Campinas: Navegando, 2011.

MOURA, D. H. Educação básica e educação profissional e tecnológica: dualidade histórica e perspectivas de integração. Holos, Natal, v. 2, ano 23, p. 4-30, 2007. Disponível em: http://www2.ifrn.edu.br/ojs/index.php/HOLOS/article/view/11. Acesso em: 21 dez. 2019.

RAMOS, M. Ensino médio integrado: ciência, trabalho e cultura na relação entre educação profissional e educação básica. In: MOLL, J. (org.). Educação profissional e tecnológica no Brasil contemporâneo: desafios, tensões e possibilidades. Porto Alegre: Artmed, 2010. p. 42-57.

RAMOS, M. Ensino médio integrado: lutas históricas e resistências em tempos de regressão. In: ARAÚJO, A. C.; SILVA, C. N. N. (orgs.). Ensino médio integrado no Brasil: fundamentos práticas e desafios. Brasília: Ed. IFB, 2017. p. 20-43.

SACRISTÁN, J. G. O que significa o currículo? In: SACRISTÁN, J. G. (org.).

Saberes e incertezas sobre o currículo. Porto Alegre: Penso, 2010. p. 16-35.

SANTOMÉ, J. T. Globalização e interdisciplinaridade: o currículo integrado. Porto Alegre: Artes Médicas, 1998.

SAVIANI, D. Trabalho e educação: fundamentos ontológicos e históricos. Revista Brasileira de Educação, Rio de Janeiro, v. 12, n. 32, p. 152-165, jan./abr. 2007. Disponível em: http://www.scielo.br/scielo.php?pid=S141324782007000100012\&script=sci abstract\&tlng=pt. Acesso em: 21 dez. 2019. 
Revista Brasileira da Educação Profissional e Tecnológica, v. 1, n. 20, e10657, 2021, p. 14 de 14 CC BY 4.0 | ISSN 2447-1801 | DOI: https://doi.org/10.15628/rbept.2021.10657

YOUNG, M. Para que servem as escolas? Educação e Sociedade, Campinas, vol. 28, n. 101, p. 1287-1302, set./dez. 2007. Disponível em:

http://www.scielo.br/pdf/es/v28n101/a0228101.pdf. Acesso em: 11 dez. 2019. 